\title{
Impact of Biocomponent Additive to Diesel Oil on Values of Selected Functional Parameters of Transport Means
}

\author{
Marietta Markiewicz ${ }^{1}$, Łukasz Muślewski ${ }^{1 *}$, Michał Pająk ${ }^{2}$ \\ ${ }^{1}$ UTP University of Science and Technology, Bydgoszcz, Poland \\ ${ }^{2}$ UTH University of Technology and Humanities, Radom, Poland
}

Received: 24 October 2019

Accepted: 29 December 2019

\begin{abstract}
The most common indicators used for assessing combustion engines powered by renewable fuels with simultaneous fuel injection are: power, torque, fuel consumption, noise emission, amount of particulates present in the exhaust fumes and composition of exhaust fumes (oxygen, carbon dioxide, hydrocarbons, nitric oxides and air excess coefficient). The aim of this study is to analyze the impact of the addition of fatty acid methyl esters to diesel oil on the value of transport means performance parameters, particularly the level of noise generated by the transport means drive units. Generating noise by internal combustion piston engines is the effect of their operation. Our study compared emissions of sound generated by diesel oil powered with diesel oil and the mixture of $30 \%$ of fatty acid methyl esters (biocomponents) and 70\% of diesel oil. The object of the study is the piston combustion engine with self-ignition of $80 \mathrm{~kW}$ rated power. The experiment was conducted for four scopes of the fuel controller's settings: standard ones, increased for $2 \%, 4 \%$, and $6 \%$ dosage of fuel and supercharging for $50 \mathrm{mb}$. We found that the increased dosages of fuel at powering with diesel oil without the additive of biocomponent influences the increase of the noise level within the whole tested scope.
\end{abstract}

Keywords: noise emission, combustion engine, biocomponent, analysis of regression, diffused modelling

\section{Introduction}

The structure of combustion engines enables their modernization and, consequently, a return to the idea of plant fuels. Running out of petroleum fuels is an argument opting for resuming the plant fuel concept.

*e-mail: lukasz.muslewski@utp.edu.pl
Crude oil occupies the first place in the structure of the natural energy sources' consumption [1]. Diesel oil, the share of which in the total processing amounts to from $34 \%$ to $41 \%$, while petrol is $20 \%$ [2], is the main product of the crude oil's refinement.

The European Union predictions indicate an increase in diesel oil use in the transportation sector and maintaining its constant use as an engine fuel. The legal conditionings of the European Union, which determine the biofuel's path of development, have an impact on 
the fuel market situation in Poland. The basic legal act since 2003 to 2009 that has determined the development of the biofuel market was directive 2003/30/WE, which obliged, out of concern for the natural environment, the Member states of the EU to add methyl esters to transportation fuels at a minimum volume of $5,75 \%$ by the end of 2010 [3]. In 2009 the European Parliament introduced new provisions in directive 2009/28/WE, which imposes an obligation of the biofuels' share in the transportation sector amounting to $10 \%$ by the end of 2020. This directive also determines the balanced development criteria concerning classification of biofuels to the renewable energy source category [4]. Two components used in engines with spark ignition and with self-ignition, bioethanol and the fatty acid methyl esters, are of basic importance on the biofuel market.

In the study a focus is put on additives applied to fuel engines with self-ignition. The following oils are counted among the group of plant fuels: arachis, rape, corn, linseed, ricinus, palm, and soya. Rape is one of the most popular plants for production of alternative fuels. A mixture of diesel oil and transesterified diesel oil powers engines with self-ignition. Transesterified diesel oils are fatty acid methyl esters characterized by much better lubricating properties than the traditional diesel oil, considerably extending engine life [5]. There are also many pro-ecological arguments opting for the use of this mixture, such as no pollution of the environment with sulfur compounds and a decrease of the $\mathrm{CO}_{2}$ volume introduced to the atmosphere [5]. Apart from combustion gas emissions, noise coming into being at the time of a combustion engine's operation is one of the most important factors determining the engine operation arduousness. The sources of noise in an engine include suction murmurs, effects of the mechanical engine parts and fixtures contact, and most of all the process of fuel combustion and its removal from the engine via the exhaust system [6]. The drive units' technological development allows for the improvement of their operation's quality, including imitation of the level of emitted sounds reduction of their arduousness for the environment [7].

It must be remembered, though, that noise emission is one of many parameters of a drive unit. Literature provides analyses of tests of engine efficiency, fuel consumption and components of exhaust gases including particulates. Efficiency tests of engines powered by biofuels have been conducted in many research centers. They have all confirmed changes in the engine performance parameters including an increase in fuel flow resistance, increases in fuel thickness, and decreases in engine overall efficiency [8-12]. Literature provides numerous analyses concerning fuel consumption which indicate that self-igniting engines need more fuel when powered by mixtures of fatty acid methyl esters and diesel oil [13-15]. Fuel consumption in a combustion engine increases by about $18 \%$ for each addition of $35 \%$ of fatty acid methyl esters to diesel oil, as compared to pure diesel oil [16]. Change in a unit fuel consumption can already be observed for a $5 \%$ addition of biocomponents to diesel oil [17-20]. Numerical, which characterize the operation of combustion engines, serve as determinants of their operation to be

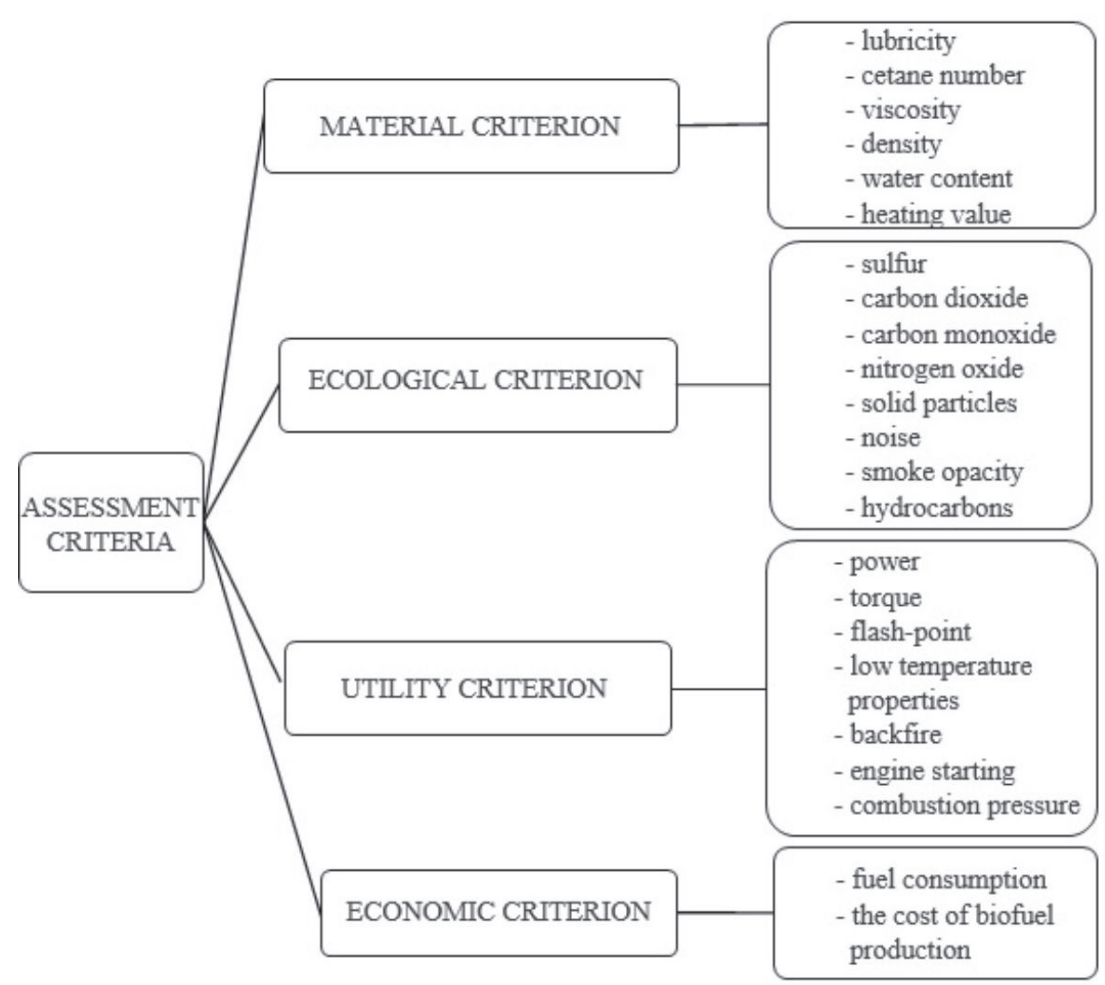

Fig 1. Criteria for assessing transport means drive unit. 
used for their assessment and comparison. An analysis of these quantities provides detailed information on the combustion engine characteristics. Based on literature analysis, criteria for assessment of a transport means drive unit powered by mixtures of diesel oil and biocomponent have been determined.

We must highlight, though, that the most commonly used indicators of piston combustion engines are: power, torque, fuel consumption, noise emission and composition of exhaust fumes and exhaust smoke. Tests conducted by other authors have provided 7\% lower values of the engine performance parameters and lower power reduction as compared to diesel, depending on the combustion system and characteristics of the injection unit $[21,22]$. According to literature, using renewable energy sources to power combustion engines reduces emission of pollution of such exhaust components as: carbon monoxide, hydrocarbons and particulates [14, 17, 23-30]. Nitric oxides, which indicate an increase by several percent as compared to diesel, are exceptions.

Based on literature, eight performance parameters were identified to be evaluated in terms of the impact on the analyzed research object functioning. These parameters were selected because of their significant influence on functioning of the drive unit powered by mixtures of diesel oil and fatty acid methyl esters. The parameters identified for engines powered by renewable fuels with simultaneous adjustment of fuel injection controller include engine noise emission and the quantity of particulates in exhaust gases (oxygen, carbon monoxide, hydrocarbons, nitric oxides and air excess coefficient). The results of measurements of the above-listed parameters were statistically analyzed to be included in the proposed method for assessing the research object functioning. On this basis an assessment model was developed for evaluation of the impact of fatty acid methyl ester additives to diesel oil on transport means functioning, which was verified using fuzzy logic elements. Based on the method of mean fuzzy diagrams, the parameters that are sensitive to fuel mixture change were identified. Fig. 2 shows a gradient form of fuzzy medians. Performance parameters are shown as decreasing in consistence with their

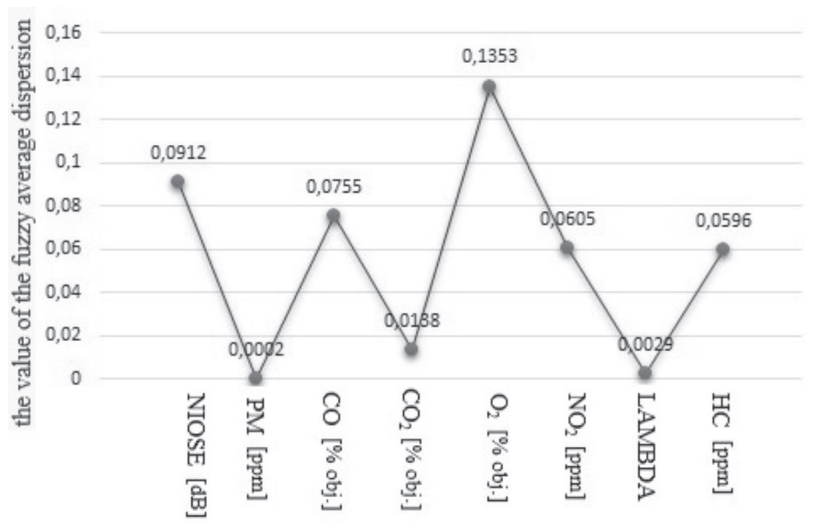

Fig 2. Gradient shape of fuzzy median. scatter value. An analysis of the obtained data and its interpretation provide the basis for an assumption that the values of performance parameters whose scatter value is lower than 0,04 significantly change depending on the type of fuel used to power the drive unit of the analyzed transport means.

Based on the values of fuzzy median scatter, parameters such as noise, carbon monoxides, oxygen, nitric oxides and hydrocarbons are sensitive to change of the fuel mixture change.

This study presents a fragment of research on a self-ignition engine powered by mixtures of diesel oil and fatty acid methyl esters for variable settings of the fuel injection controller. The study goal is to analyze the influence of fatty acid methyl ester addition to diesel oil on the value of transport means performance parameters, particularly the level of noise emission produced by the drive units of the research objects. However, the practical goal is to determine an optimal setting for the fuel injection controller for different compositions of the fuel mixture, in terms of performance parameters of a transport means drive unit.

This study includes a description of the noise emission test for a drive unit fueled by a mixture of $70 \%$ diesel oil and $30 \%$ of fatty acid methyl esters for five fuel injection controller settings and an analysis of the results. The noise generated by the research object is presented as one of the performance parameters due to its sensitivity to the fuel mixture composition change and the fuel injection controller setting.

As other authors state, the reduction of noise in the diesel engine also takes place in the study of combustion of diesel oil with various types of oxygenates. In various world scientific units, experimental tests were conducted out on a diesel engine in order to investigate the mechanisms of combustion noise formation for various alternative fuels of the mixture. However, in no studies were the settings of the fuel injection driver modified [31].

\section{Material and Methods}

Oils subject to the transesterification process, that is the exchange of chemically bound glycerin into triacylglycerol particle on the added methyl alcohol in the presence of basic or acidic catalyst and commonly called biocomponents, are the materials used for the studies. The tested biocomponents were mixed with diesel oil in the proportion $30 \%$ of biocomponent and $70 \%$ of diesel oil.

The studies on the properties of engines with selfignition powered with plant oil or with the mixture of plant oil with diesel oil were conducted at many research and development centers, taking into consideration the studies on the engine basic parameters. The analyses of the study results presented by different authors concern problems related to the application of plant oil as an 
Table 1. Basic size and style requirements.

\begin{tabular}{|c|c|}
\hline \multicolumn{2}{|c|}{ ENGINE 1.6 HDi } \\
\hline Type of the engine & With self-ignition \\
\hline Fuel type & Diesel oil \\
\hline Engine cubic capacity & $1560 \mathrm{~cm}^{3}$ \\
\hline Engine power & $\begin{array}{c}110 \mathrm{KM}(81 \mathrm{~kW}) \text { at } 4000 \\
\text { rev/min }\end{array}$ \\
\hline Maximum torque moment & $240 \mathrm{Nm}$ at 1750 rev/min \\
\hline Number of cylinders & 4 \\
\hline Cylinders' lay-out & $73 \mathrm{~mm}$ \\
\hline Cylinder's diameter & 88,3 mm \\
\hline Piston stroke & 16 \\
\hline Number of valves & Direct, common rail \\
\hline Type of ignition & Turbo-compressor's forced \\
induction
\end{tabular}

engine fuel [32]. An engine with self-ignition, which is used by the means of road transportation, was covered by the studies. Characteristics of the drive unit used in the studies are presented in Table 1.

A drive unit used in the studies is extensively applied in vehicles of the permissible total weight not exceeding 3,5 t. The tested engine is characterized by a direct fuel injection performed with the use of the common rail system and the applied electro-magnetic injectors. The drive unit cooperates with a turbo-compressor of variable geometry of blades and dual mass flywheel, which contributes to performance improvement and allows it to meet stringent standards of exhaust gas emissions. The research object of the studies was not equipped with a diesel particulate filter. The tested engine was a 16-valve version having the timing belt driving one camshaft, while the other one, via chain, receives the drive from the first one. The disadvantage of the drive unit, noticed during the vehicle diagnostics performed after the tests, is the unsealing of the lubrication system after longer exploitation and turbocompressor breakdowns.

Adaptation of the drive system was performed in the object, which made it possible to change the fuel without any damage to the engine. The performed changes concerned the following: fuel supply system, installation of an additional fuel tank, computer software.

The conducted modifications did not interfere with the engine structure. They only concerned the fittings and software. Adaptations connected with the mixture supply to the engine consisted only in the installation of an internal tank, at simultaneous cutting off the liquid inflow from the factory tank. During the tests, neither additional fuel filters nor an additional fuel pump was installed in the engine. The fuel supply system was connected from the external tank directly to the drive unit.

The conducted tests concerned the measurements of the performance parameter of the means of transport powered with the diesel oil with $30 \%$ addition of the fatty acid methyl esters. Measurement of noise emission generated by the drive unit was subject to the tests. The experiment was conducted in the number of 64 repetitions in the laboratory environment with the use of the chassis dynamometer. The tests were conducted for different settings of fuel injection: for standard ones, fuel dose increased by $2 \%$ and increased supercharging $50 \mathrm{hPa}$, fuel dose increased by $4 \%$ and increased supercharging $50 \mathrm{hPa}$, fuel dose increased by $6 \%$ and increased supercharging $50 \mathrm{hPa}$, and the increased fuel dose by $6 \%$ and increased supercharging $150 \mathrm{hPa}$. Changes made to the factory software of the engine computer were an innovative aspect. No studies have been found in domestic and foreign literature in which modifications of the fuel injection controller settings have been made.

The sound generated by the drive unit was determined with the use of a sonometer with a builtin spectrum analyzer meeting the standard IEC 616721:2002 and the standard IEC 60651. The principle of the analyzer's operation was based on testing the acoustic signal, which in the form of a pressure wave comes to the capacitor microphone of linear frequency characteristics. During testing of the electric capacity's changes, the membranes connected with vibrations were converted into correct voltage changes. A signal formed in such a manner reached the amplifier, and then through the filtering systems to the output system. Reaching by signal the outlet system made it possible to read the measurement's result on the device's digital display. The measuring device was equipped with correction filters, the feature of which is to adjust the characteristics of the carried sound to a human's ear characteristics.

Determining the acoustic parameters of a drive unit powered with a mixture of $70 \%$ diesel oil and $30 \%$ fatty acid methyl esters took place with the survey method aiming at determination the engine's noise acoustic power level. That method consisted in calculating the adjusted level of acoustic power and the level of the acoustic power in the frequency bands on the basis of the acoustic pressure level in the frequency bands and the sound level measured with the use of a correction filter.

\section{Results and Discussion}

For the purposes of creating a model which in the best manner would foresee the changes of the variable value, regression analysis was used. At the time of that 
Table 2. Values of the basic statistics for all the analysed settings of the fuel injection controller for the diesel oil.

\begin{tabular}{|c|c|c|c|c|c|}
\hline Number of the test & 1 & 2 & 3 & 4 & 5 \\
\hline Dope & 0 & 2 & 4 & 6 & 6 \\
\hline Supercharging & 0 & 50 & 50 & 50 & 150 \\
\hline Medium & 121,62 & 121,39 & 121,73 & 128,95 & 128,85 \\
\hline Median & 121,50 & 121,20 & 121,80 & 128,90 & 128,90 \\
\hline Standard deviation & 0,40 & 0,40 & 0,27 & 0,33 & 0,19 \\
\hline Variability coefficient & 0,003 & 0,003 & 0,002 & 0,003 & 0,001 \\
\hline Min & 121 & 120,9 & 121,1 & 128,5 & 128,4 \\
\hline Max & 122,4 & 122,2 & 122,2 & 129,5 & 129,1 \\
\hline
\end{tabular}

Table 3. Values of the basic statistics for all the analyzed settings of fuel injection, for the mixture of the diesel oil with biocomponent.

\begin{tabular}{|c|c|c|c|c|c|}
\hline Number of the test & 1 & 2 & 3 & 4 & 5 \\
\hline Dope & 0 & 2 & 4 & 6 & 6 \\
\hline Supercharging & 0 & 50 & 50 & 50 & 150 \\
\hline Medium & 121,00 & 120,76 & 120,53 & 120,54 & 120,61 \\
\hline Median & 121,10 & 120,70 & 120,60 & 120,60 & 120,60 \\
\hline Standard deviation & 0,79 & 0,12 & 0,34 & 0,43 & 0,48 \\
\hline Variability coefficient & 0,007 & 0,001 & 0,003 & 0,004 & 0,004 \\
\hline Min & 119,5 & 120,6 & 119,9 & 119,7 & 119,8 \\
\hline Max & 122,6 & 120,9 & 121 & 121,1 & 121,3 \\
\hline
\end{tabular}

analysis, using it was assumed, that the dependencies between the variables were linear dependence and also the linear regression's equation was determined. For analysis of the noise dependence (Y) on the dose (X1) and supercharging (X2), the linear regression in the form $\mathrm{Y}=\mathrm{c}+\mathrm{b}^{*} \mathrm{x} 1+\mathrm{a}^{*} \mathrm{x} 2$ was used. For the regression equation, the multiple correlation coefficient $\mathrm{R}$ was calculated. Testing of the hypothesis $\mathrm{H} 0: \mathrm{R}=0$ was equivalent with the regression equation's significance testing. Rejection of the hypothesis $\mathrm{H} 0: \mathrm{R}=0$ means significance of the regression's equation. At the next stage of analysis we tested the

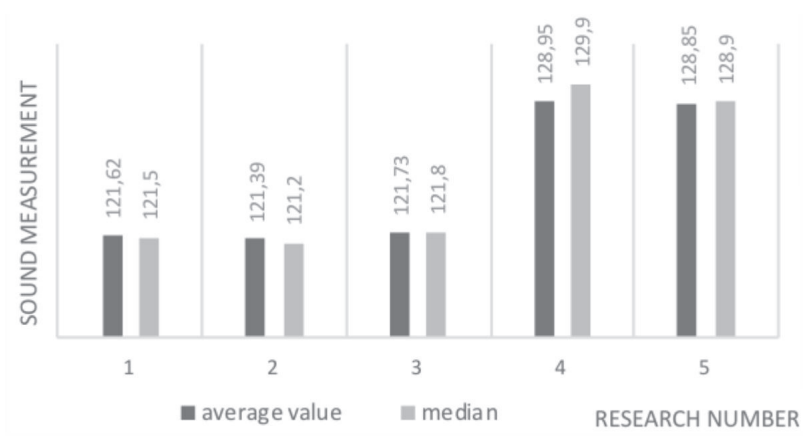

Fig. 3. Mean values and median of the sound measurement results for the diesel oil. significance of the regression's equation coefficients. These were the hypotheses in the form of $\mathrm{HO}: \mathrm{b}=0$ and $\mathrm{H} 0: \mathrm{a}=0$.

The statistical analysis concerned 64 measurements of the drive unit's sound emissions, for the diesel oil and the mixture of $30 \%$ of fatty acids methyl esters and $70 \%$ of diesel oil in all the fuel injection controller's settings. The values of the basic statistics for all the analysed fuel injection controller's settings for the diesel oil and for the mixture of the diesel oil with the biocomponents are presented in Tables 2-3. Figs 3-4 show the graphic form presenting the mean values and

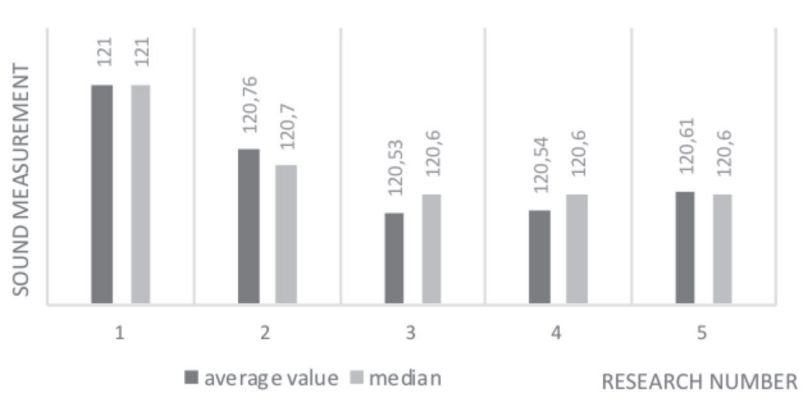

Fig. 4. Average values and the median of the sound measurement results for the mixture of $30 \%$ of biocomponent and $70 \%$ of diesel oil. 
the median for the diesel oil and for the mixture of the diesel oil and for the mixture of the diesel oil and the biocomponent.

Based on the analysis of data presented in Table 2, one may notice that the mean values and the median in the last two columns are significantly higher than in the first three columns. Attention should be especially paid to the low variability coefficient, not exceeding $0,07 \%$.

Analysis of the values presented in Table 3 shows that the values of the standard deviation and of the variation coefficient are the highest ones in the first column.

\section{Analysis of Regression}

In order to study the dependencies of the values of noise $\mathrm{Y}$ for the diesel oil and the dope $-\mathrm{X}_{1}$ and supercharging $-\mathrm{X}_{2}$, the equation of the multi-factor linear regression for the diesel oil has been determined:

$\mathrm{Y}=119,7996+1,209262 * \mathrm{X}_{1}+0,005923 * \mathrm{X}_{2}$

...where $\mathrm{X}_{1}$ is dope of fuel, $\mathrm{X}_{2}$ is supercharging and $\mathrm{Y}$ is noise.

The equation is statistically significant at $\mathrm{p}<0,0001$. The multiple correlation coefficient equals $\mathrm{R}=0,8436$. The coefficient 1,209262 is statistically significant at $\mathrm{p}<0,0001$, while the coefficient 0,005923 is not statistically significant.

The multi-factor linear regression's equation has also been determined for the mixture of $30 \%$ of fatty acid methyl esters and $70 \%$ of diesel oil:

$$
\mathrm{Y}=120,928-0,0811 * \mathrm{X}_{1}+0,00088 * \mathrm{X}_{2}
$$

...where $\mathrm{X}_{1}$ is dope of fuel, $\mathrm{X}_{2}$ is supercharging and $\mathrm{Y}$ is noise.

The equation is statistically significant at $\mathrm{p}<0,0001$. The multiple correlation coefficient is equal to $\mathrm{R}=0,3121$. The coefficient $-0,0811$ is statistically significant at $p<0,0001$, while the coefficient 0,00088 is not statistically significant. For the mixture of the diesel oil and the component, the dope's increase results in the decrease of the noise's value.

\section{Fuzzy Analysis of the Values of the Considered Operating Parameter}

In order to verify the obtained results of the tests, the fuzzy analysis of the considered operating parameter has also been conducted. The registered values of the noise generated at the studied object's operation have been analyzed. Just as for each study of the operating parameter [33-37], as well as for the noise level analyzed in the study, there have been introduced characteristic values in the form of: minimum, boundary and maximum values, and also characteristic ranges of the possible, admissible and inadmissible values described with expressions (4-5) and presented in Fig. 5:

$$
\begin{aligned}
& \mathrm{H}_{\mathrm{P}}=\left[\mathrm{h}_{\text {min }}, \mathrm{h}_{\text {max }}\right] \\
& \mathrm{H}_{\mathrm{D}}=\left[\mathrm{h}_{\text {min }}, \mathrm{h}_{\mathrm{gr}}\right] \\
& \mathrm{H}_{\mathrm{ND}}=\left[\mathrm{h}_{\mathrm{gr}}, \mathrm{h}_{\text {max }}\right]
\end{aligned}
$$

...where:

$\mathrm{h}_{\min }-$ minimum noise emission value

$\mathrm{h}_{\mathrm{gr}}$ - boundary noise emission value

$\mathrm{h}_{\max }-$ maximum noise emission value

$\mathrm{H}_{\mathrm{p}}$ - range of possible values

$\mathrm{H}_{\mathrm{D}}$ - range of admissible values

$\mathrm{H}_{\mathrm{ND}}$ - range of inadmissible values

Registered noise emission values as the measurement values are determined with approximation, which during the studies have been modelled in the form of fuzzy sets [38, 39]. Based on each series of 64 measurements, the flat fuzzy set type u $\Lambda$, corresponding to the noise emission's value in form (6), has been defined.

$$
\mathrm{FS}_{\Lambda}(\mathrm{x})=\left\{\begin{array}{l}
0 \Leftrightarrow \mathrm{x} \leq \operatorname{lrs} \vee \mathrm{x} \geq \mathrm{rrs} \\
\frac{\mathrm{x}-\mathrm{lrs}}{\operatorname{lrk}-\operatorname{lrs}} \Leftrightarrow \operatorname{lrs}<x \leq \operatorname{lrk} \\
\frac{\mathrm{rrs}-\mathrm{x}}{\mathrm{rrs}-\mathrm{lrk}} \Leftrightarrow \operatorname{lrk}<x<\operatorname{rrs}
\end{array}\right.
$$

...where:

$F S_{\Lambda}(x)$ - membership function of the fuzzy set type $\Lambda$ $x$ - element of the fuzzy set domain

lrk - minimum value of the fuzzy set's nucleus

lrs - minimum value of the fuzzy set's carrier

rrs - maximum value of the fuzzy set's carrier

The mean value of the series is the modal value of the set where the lowest and the highest values of the set's carrier is the minimum and the maximum value in the series. Introduction of the measurement value modelling with the use of fuzzy sets implicates modelling of diffused values and characteristic ranges, which is why the minimum value is expressed in the form of the fuzzy set type $L$, maximum value in the form of the set type $\Gamma$, and the boundary value in the

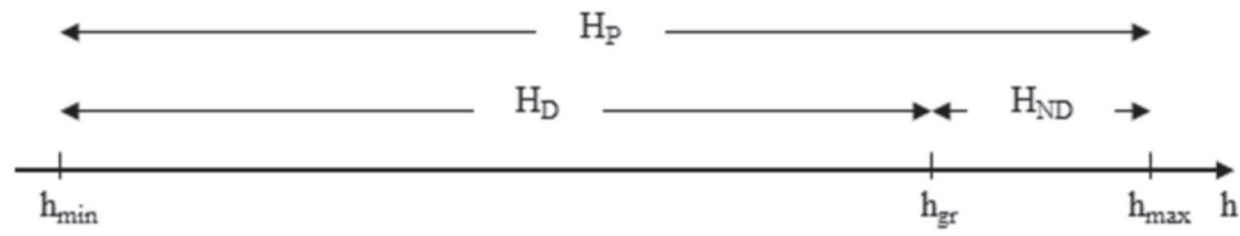

Fig. 5. Value and characteristic ranges of noise emissions. 
Table 4. Values describing fuzzy sets for the characteristic values and ranges.

\begin{tabular}{|c|c|c|c|c|}
\hline Fuzzy set & $\begin{array}{c}\text { Minimum carrier's } \\
\text { value }\end{array}$ & $\begin{array}{c}\text { Nucleus minimum } \\
\text { value }\end{array}$ & $\begin{array}{c}\text { Nucleus maximum } \\
\text { value }\end{array}$ & $\begin{array}{c}\text { Maximum carrier's } \\
\text { value }\end{array}$ \\
\hline Minimum value & 0 & 0 & 0 & 0,78 \\
\hline Boundary value & 121,0 & 121,62 & 121,62 & 122,4 \\
\hline Maximum value & 128,72 & 129,5 & 129,5 & 129,5 \\
\hline Range of admissible values & 0 & 0 & 121,62 & 122,4 \\
\hline Range of unadmissible values & 120,84 & 121,62 & 129,5 & 129,5 \\
\hline
\end{tabular}

form of the set $\Lambda$ [40]. Analogously, the ranges of admissible and unadmissible values have been modelled in the form of fussy sets type $\Pi$.

Based on the conducted measurements, it has been assumed that the boundary value there shall be the value of the noise emission corresponding to the engine's standard settings and combustion of diesel oil without additives. Value 0 has been assumed to be the minimum value, and the maximum value is the maximum value registered during the tests. The spheres of admissible and inadmissible value diffusion of sets were assumed as equal to the sphere of diffusion of the boundary values set. In such a manner there has been received the division of the analysed parameter domain presented in Fig. 6. Detailed values of the obtained fuzzy sets are presented in Table 4.

Making use of the introduced fuzzy values and characteristic ranges, the power of the common part of the fuzzy set of admissible values and the fuzzy noise emission set have been calculated for each measurement series. It has been assumed that if the power of the common part is lower than the power of the noise emission fuzzy set, then the value of the noise emission for the series belongs to the range of inadmissible values. On that basis it has been determined that the noise emission for the cases of diesel oil combustion at the dope of fuel of 4 and $6 \%$, and supercharging $50 \mathrm{mbar}$ and $150 \mathrm{mbar}$, reaches inadmissible values.

Then, for the remaining cases of engine operation, the power of the common part of the fuzzy set of the boundary value and the noise emission value has been calculated. If that power equals zero, then the value of the noise emission belongs to the range of admissible values distant from the boundary values. On that basis it was determined that the noise emission for combustion of diesel oil with the additive of biofuel at the dope of the fuel 2 and $4 \%$ and supercharging of $50 \mathrm{mbar}$ reached the values distant from the boundary ones.

For the remaining case, that is for diesel oil combustion at the dope of the fuel of $2 \%$ and supercharging of 50 mbar and combustion of the diesel oil with the additive of biofuel at the standard settings and the dope of the fuel of $6 \%$ and supercharging 50 and $150 \mathrm{mb}$, the noise emission level belonged to the admissible values but reached the boundary value limit.

\section{Conclusions}

On the basis of the conducted studies it may be found that the addition of fatty acid methyl esters has an impact on the sound level emitted by the analysed object of the studies. The conducted statistical analysis showed a lowered level of noise emitted by the drive unit, which was powered with a mixture of $30 \%$ fatty acid methyl esters and $70 \%$ of diesel oil. It also should be noted that for that mixture, sound emission has considerably decreased at the change of the fuel injection controller's settings, which is the increase of the fuel dose by $6 \%$ and supercharging increase by $50 \mathrm{hPa}$ and $150 \mathrm{hPa}$. Based on the determined regression equations, it may be found that the obtained results were statistically significant, and the increase of the fuel dope shall result in the drop of sound emissions generated by the engine. The multiple correlation coefficient for the diesel oil amounted to 0,8436 , and

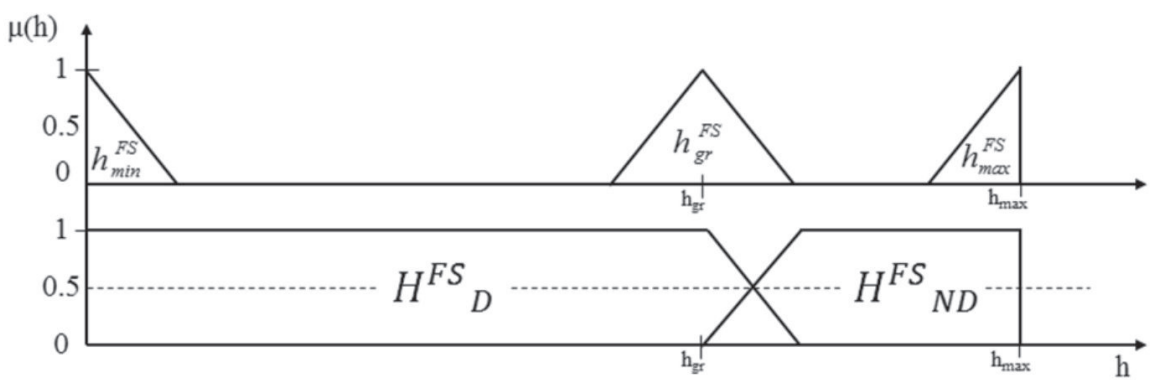

Fig. 6. Fuzzed values and characteristic ranges of noise emission. 
for the diesel oil and biocomponent mixture it was equal to 0,3121 . As a result of the use of the fuzzed emitted noise value it was determined that emission of sound generated by the drive unit powered with a mixture of the diesel oil and the fatty acid methyl esters and supercharging reached the boundary values as compared to the standard settings of the fuel injection's controller.

It should be stressed that the studies and analysis of the emitted noise level by the drive units powered with fuel with the addition of a biocomponent is a significant and current research problem. Noise, as one of the main operating parameters, directly affects the natural environment and influences the human-factor engineering of an operator's workplace.

The obtained results of operating studies are grounds for further author studies aimed at checking the adequacy of the formed conclusions for a general group of objects that may be powered with the analyzed mixtures of fuels.

\section{Acknowledgements}

The authors would like to thank the University of Life Sciences in Lublin and the Slovak University of Agriculture in Nitra for providing selection and cooperation positions.

\section{Conflict of Interest}

The authors declare no conflict of interest.

\section{References}

1. EUROPEA COMMISSION, European Union Energy Outlook to 2020. Brusseles, 2020.

2. YUSUF N., Kamarudin K., YAAKUB Z. Overview on the current trends in biodiesel production. Energy Conversion and Management. 52, 2011.

3. DIRECTIVE 2009/28/WE of the European Union Parliament and Council of 23 April 2009 on renewable energy sources promotion, amending and subsequently repealing directive 2001/77/WE and 2003/WE (Dz. Urz. UE L 140).

4. DIRECTIVE 2003/30/WE of the European Union Parliament and Council of 8 May 2003r. on support of biofuels or other renewable fuel application in transport (Journal of Laws. UE L 123).

5. DEMIRBAS A., Global Renewable Energy Projections, Energy Sources. 4, 2009.

6. KOMOROWSKA I., GÓRNICKA D. Adaptation of engine vibration characteristics for diagnostics of mechanical defects. Internal combustion engines. 50 (3), 2009.

7. MUŚLEWSKI Ł. Evaluation Method of Transport Systems Operation Quality. Polish Journal of Environmental Studies. 18, 2009.

8. GANG W., GUOHE J., ZHIYUAN Y., ZHIJIAN H., Emission Characteristics for Waste Cooking Oil Biodiesel
Blend in a Marine Diesel Propulsion Engine, Polish Journal of Environmental Studies. 28, 2019.

9. HIRKUDE J., PADALKAR A. Performance and emission analysis of a compression ignition: Engine operated on waste fried oil methyl esters. Applied Energy. 90, 2012.

10. MASERA K., HOSSAIN A. Biofuels and thermal barrier: A review on compression ignition engine performance, combustion and exhaust gas emission. Journal of the Energy Institute. 92, 2019.

11. ASADIA A., ZHANGB Y., MOHAMMADI H., KHORAND H., RUI Z., HOSSEIN DORANEHGARD M., BOZORGE M. Combustion and emission characteristics of biomass derived biofuel, premixed in a diesel engine: A CFD study. Renewable Energy. 138, 2019.

12. MOFIJUR M., RASUL M., HYDE J., BHUYIA M. Role of Biofuels on IC Engines Emission Reduction. Energy Procedia. 75, 2015.

13. ZIVKOVIC S., VELJKOVIĆ M., Environmental impacts the of production and use of biodiesel, Environmental Science and Pollution Research. 25, 2018.

14. FONTARAS G., KARAVALAKIS G., KOUSOULIDOU M., TZAMKIOZIS T., NTZIACHRISTOS L., BAKEAS E., STOURNAS S., SAMARAS Z. Effects of biodiesel on passenger car fuel consumption, regulated and nonregulated pollutant emissions over legislated and realworld driving cycles. Fuel. 88, 2009.

15. LIE X., MUPONDWA E. Life cycle assessment of camelina oil derived biodiesel and jet fuel in the Canadian Prairies. Science of The Total Environment. 481, 2014.

16. ILERI E., KOCAR G. Effects of antioxidant additives on engine performance and exhaust emissions of a diesel engine fueled with canola oil methyl ester-diesel blend. Energy Conversion and Management. 76, 2013.

17. OZER C., OZTURKA E., SOLMAZB H., AKSOYC F., ÇINARB C., YUCESUB S. Combined effects of soybean biodiesel fuel addition and EGR application on the combustion and exhaust emissions in a diesel engine. Applied Thermal Engineering. 95, 2016.

18. LUOA Z., PLOMERA M., LUA T., SOMB S., LONGMANB D., MANI S., WILLIAM S., PITZC J. A reduced mechanism for biodiesel surrogates for compression ignition engine applications. Fuel. 99, 2012.

19. HOEKMANA K., BROCHA A., ROBBINSA C., CENICEROSA E., NATARAJANB M. Review of biodiesel composition, properties, and specifications. Renewable and Sustainable Energy Reviews. 16, 2012.

20. RAJAGOPAL D., HOCHMAN G., ZILBERMAN D. Indirect fuel use change (IFUC) and the lifecycle environmental impact of biofuel policies. Energy Policy. 39, 2011.

21. AZOUMAHA Y., BLINAC J., DAHOB T. Exergy efficiency applied for the performance optimization of a direct injection compression ignition engine using biofuels. Renewable Energy. 34, 2009.

22. TOMPKINS B., SONG H., BITTLE J. JACOBS T., Efficiency considerations for the use of blended biofuel in diesel engines. Applied Energy. 98, 2012.

23. MAN X., CHEUNG C., NING Z., WEI L., HUANG $Z$. Influence of engine load and speed on regulated and unregulated emissions of a diesel engine fueled with diesel fuel blended with waste cooking oil biodiesel. Fuel. 180, 2016.

24. ARMAS O., YEHLIU K., BOEHMAN A. Effect of alternative fuels on exhaust emission during diesel engine operation with matched combustion phasing. Fuel. 89, 2010. 
25. CHAUHAN B., KUMARA N., CHOB H., LIMC H. A study on the performance and emission of a diesel engine fueled with Karanja biodiesel and its blends. Energy. 56, 2013.

26. HOEKMAN S., ROBBINS C. Review of the effects of biodiesel on NOx emissions. Fuel Processing Technology. 96, 2012.

27. NECATI A., CANAKCI O. Determination of performance and combustion characteristics of a diesel engine fueled with canola and waste palm oil methyl esters. Energy Conversion and Management. 52, 2011.

28. OZENER O., YUKSEK L., ERGENÇ T., OZKAN M. Effects of soybean biodiesel on a DI diesel engine performance, emission and combustion characteristics. Fuel. 115, 2014.

29. XUE J., GRIFT T., HANSEN C. Effect of biodiesel on engine performances and emissions. Renewable and Sustainable Energy Reviews. 15, 2011.

30. RAKOPOULOS C., DIMARATOS A., GIAKOUMIS E., RAKOPOULOS D. Study of turbocharged diesel engine operation, pollutant emissions and combustion noise radiation during starting with bio-diesel or n-butanol diesel fuel blends. Applied Energy. 88, 2010.

31. MARKIEWICZ M., MUŚLEWSKI Ł. The Impact of Powering an Engine with Fuels from Renewable Energy Sources including its Software Modification on a Drive Unit Performance Parameters. Sustainability. 11 (23), 2019.

32. GUMUS M., KASIFOGLU S. Performance and emission evaluation of a compression ignition engine using a biodiesel (apricot seed kernel oil methyl ester) and its blends with diesel fuel. Biomass and Bioenergy. 34, 2010.
33. MUŚLEWSKI $Ł$. The implementation of the fuzzy logic elements in the area of the transport system operation quality assessment. Maritime Industry. Ocean Engineering and Coastal Resources. Maritime Transportation. Taylor \& Francis Group. Balkema. London-Leiden-New YorkPhiladelphia-Singapore. 1, 2007.

34. PAJĄK M. The space of a feature of a complex technical system. Scientific Problems of Machines Operation and Maintenance, ITeE - PIB. 2, 2010.

35. WOROPAY M., MUŚLEWSKI Ł. Quality in terms of system. ITeE-PIB. Radom. 2005

36. PAJĄK M. Fuzzy modelling of cardinal features of a complex technical system. Risk, Reliability and Safety: Innovating Theory and Practice. CRC Press Taylor \& Francis Group. ESREL 2016 European Safety and Reliability Conference. Glasgow. 2016.

37. MOHAN C. An Introduction to Fuzzy Set Theory and Fuzzy Logic. Viva Books. 2015.

38. LANDOWSKI B., PAJĄK M., ŻÓŁTOWSKI B., MUŚLEWSKI Ł. Method of building a model of operational changes for the marine combustion engine describing the impact of the damages of this engine on the characteristics of its operation process. Polish Maritime Research. 2, 2017.

39. MUŚLEWSKI Ł., PAJĄK M., LANDOWSKI B., ŻÓŁTOWSKI B. A method for determining the usability potential of ship steam boilers. Polish Maritime Research. 23, 2016.

40. LANDOWSKI B, MUŚLEWSKI Ł. Decision model of an operation and maintenance process of city buses. Proceedings of 58th International Conference of Machine Design Departments - ICMD. Publisher: Czech University of Life Sciences Prague. Czech Republic. 2017. 